\title{
A textured and sensory grammar for the experience of reading
}

\author{
Ian Cushing, University College London
}

\section{Accepted manuscript for publication in English in Education}

\section{Texture}

Texture is the way in which a reader's environment, feelings and responses interact with the language of a text in order to create the experience of a fictional world (Stockwell 2005, 2009, 2016). It is the feelings of transportation and immersion, of real tears and spine tingles that we have to events that we know are not real. Most readers will be able to relate to Matilda's feelings of texture in her early stages of discovering the pleasures of reading:

It was pleasant to take a hot drink up to her room and have it beside her as she sat in her silent room reading in the empty house in the afternoons. The books transported her into new worlds and introduced her to amazing people who lived exciting lives. She went on olden-day sailing ships with Joseph Conrad. She went to Africa with Ernest Hemingway and to India with Rudyard Kipling. She travelled all over the world while sitting in her little room in an English village. (Dahl 1988: 15)

Within the discipline of stylistics, there has been a recent, increased focus on texture, where researchers have augmented stylistic 'toolkits' (e.g. Carter 2010; Wales 2014) with insights from cognitive linguistics and reader-response studies. The result - cognitive stylistics - is a systematic and coherent way of accounting for a reader's felt experience of reading, combining linguistic analyses of texts with what readers say about reading (e.g. Gavins 2007; Semino \& Culpeper 2002; Stockwell 2002; Neurohr \& Stewart-Shaw 2019). When Matilda is 'transported' during reading, she does so because the language of the text triggers a rich fictional world in her mind, which she fleshes out with her own knowledge and experience of the 'real' world. The construction, textural quality and experience of these fictional worlds form the focus of study of cognitive stylistics. Put this way, cognitive stylistics shares some of the broad aims of reader-response work, such as that by Rosenblatt (e.g. 1978), but builds on this by insisting that responses are anchored to the text. It follows then, that a typical cognitive stylistic analysis is discursive in that it combines two things: (1) a first-person, introspective, close textual analysis of the text, and (2) the kinds of things that readers say about the experiential texture of reading it.

My focus in this paper is how such concepts from cognitive stylistics can inform the teaching of literary language in secondary schools. I make the case for a 'pedagogical cognitive stylistics', whereby teachers and students use tools, concepts, metalanguage and methods from the discipline in order to engage in meaningful, contextualised literary linguistic work in the classroom, and to talk explicitly about the reading experience. This builds not just on the emerging interest in applying cognitive stylistics to schools as a pedagogy (e.g. Cushing 2018a, 2020a f.c, 2020b f.c; Cushing \& Giovanelli 2019; Giovanelli 2010,2017), but within a wider shift towards contextualised grammar pedagogies (e.g. Myhill 2018) and stylistics in schools more broadly (see Cushing 2018b for an overview). Across this research, work has argued for pedagogies which seek to integrate language and literature, rejecting false and divisionary boundaries within English (see Cushing 2018b); foreground students' reading experience as a legitimate, genuine and 'authentic' aspect of classroom discourse (e.g. Giovanelli \& Mason 2015), and challenge ideas around the teacher operating as a 'gatekeeper to meaning' (Xerri 2013). Finally, I argue for the place of cognitive stylistics as a humanistic, critical pedagogy (e.g. Pennycook 2001: 130) which sees grammar intimately tied up with meaning, senses, experience and reading, cutting across clause and discourse. This way of conceptualising grammar is, in some ways, aligned to the UK secondary curriculum, but in stark contrast to the primary curriculum, which is largely concerned with grammar as a prescriptive set of rules, confined to the level of the clause. I have discussed the incongruence between primary-secondary grammar policy elsewhere (Cushing 2019) and the need for curriculum policy to adopt a broader, more theoretically and pedagogically sound way of thinking about grammar. 
The broad research aims here then, are to examine what happens in the classroom during such a pedagogy, and to consider some of the facilitative benefits of cognitive stylistics as a tool for teachers and students to conceptualise what language is, and how it works to construct reading experiences.

\section{A sensory, experiential grammar}

Within cognitive stylistics, one of the most powerful and universally applicable ways of thinking about texture comes from Stockwell's inventory of textual attractors (Stockwell 2009: 20-30). Put simply, textual attractors are features of a text that are likely to attract a reader's attention during reading, in the same way that features of an environment attract our attention as we navigate the real world. Attractors are textual correlates and metaphorical extensions of bodily experiences and senses, in terms of how we focus towards and attenuate away from things which shift in and out of our attentional field. Stockwell presents them as a 'checklist', which can be traced through a literary text. This is as follows:

- Newness (currency: the present moment of reading is more attractive than the previous moment)

- Agency (noun phrases in active position are better attractors than in passive position)

- Topicality (subject position confers attraction over object position)

- Empathetic recognisability (human speaker $>$ human hearer $>$ animal $>$ object $>$ abstraction)

- Definiteness (definite ('the man') $>$ specific indefinite ('a certain man') $>$ nonspecific indefinite ('any man'))

- Activeness (verbs denoting action, violence, passion, wilfulness, motivation or strength)

- Brightness (lightness or vivid colours being denoted over dimness or drabness)

- Fullness (richness, density, intensity or nutrition being denoted)

- Largeness (large objects being denoted, or a very long elaborated noun phrase used to denote)

- Height (objects that are above others, are higher than the perceiver, or which dominate)

- Noisiness (denoted phenomena which are audibly voluminous)

- Aesthetic distance from the norm (beautiful or ugly referents, dangerous referents, alien objects denoted, dissonance) (Stockwell 2009: 25).

Stockwell (2009: 26) points out that the inventory 'cuts across' the traditional boundaries of grammar and experience, but that a cognitive linguistic perspective, which sees language as embodied (see Giovanelli 2014), treats these within the same category. As textual attractors are conceptual effects rather than specifically defined linguistic features, only those attractors towards the top of the list are defined in terms of grammatical characteristics, whereas those towards the bottom are defined in terms of their semantic properties. Grammar here then, is a clause and discourse-level phenomena, which is concerned with how meaning is constructed and how textual patterns correlate to embodied experience.

Attractors are dynamic in at least two ways. As readers build fictional worlds, or 'text-worlds' (Gavins 2007; Werth 1999) in their minds during reading, attractors can move into the foreground or fade into the background, which serve to create different textual evocations and the felt 'depth' of a literary work:

attention is moved around either by being shifted - this involves distraction from one figural attractor to another - or zoomed - that is, focused inward with a greater granularity or intensity. (Stockwell 2009: 34)

Secondly, texts typically consist of multiple attractors, which work together in a kind of cognitive array to produce various conceptual effects by the 'aligned co-ordination and rich iconic texture of these features' (Stockwell 2009: 31) and result in text-worlds which can feel immersive, emotionally charged and absorptive, replicating experiences from the 'real' world. Text-worlds are further fleshed out with a reader's idiosyncratic 'discourse-world' knowledge (Gavins 2007), whereby readers draw on their experiential knowledge of the world. 
The rest of this paper makes the case that the textual attractor model, along with the principles of cognitive stylistics, can be recontextualised into a pedagogy suitable for English teachers. Given that the model is built on physical experience in terms of sensory input and spatial orientation, and uses language from these domains, I suggest it can be thought of as a 'sensory and experiential grammar', used in the classroom in order to explain the ways in which texts represent physical worlds and events, and the ways in which the texture of those worlds can feel real.

\section{Recontextualising cognitive stylistics}

Work which uses Stockwell's model has been focused on the analysis of literary texts (e.g. Gavins 2012; Giovanelli 2013; Stockwell 2009). However, I see it as a valuable way in which teachers and students might come to conceptualise and describe the reading experience, and discuss the role of language in building fictional worlds. One obvious reason for this is that the model is based on what readers - albeit, limited to able-bodied readers - already know about the world, in terms of how they navigate and experience it using their five senses.

In order to assess such beliefs, I conducted a classroom-based study in which I worked closely with two secondary English teachers and their Year 8 classes in a North London school. Other work from this project is reported in Cushing (2018a, 2020a f.c., 2020b f.c) and Cushing \& Giovanelli (2019). The study was committed to collaborative and pragmatic principles in teacher-researcher work, adopting the guidelines from design-based research (DBR) (e.g. Barab 2014). In DBR, researchers and teachers collaborate to address a particular issue through the systematic design and study of intervention materials and pedagogical principles. The goal is then to study how these interventions work in practice, reflect on their effectiveness and refine until satisfactory. Postintervention, this feeds into the development and refinement of existing/new theories and pedagogical methods that can be applied to other educational contexts, and so a key facet of the approach is the knitting together of theory and practice. The pedagogy advocated for in this paper then, followed a series of principles informed by cognitive stylistics, namely that: a students' reading experience and responses forms a legitimate part of classroom discourse which ought to be at the centre of classroom activities; grammar is a clause and discourse-level phenomena, which should be explored in the context of reading experiences, and that metalinguistic concepts from cognitive stylistics serve to facilitate and describe the reading experience. Over a period of 18 months, I trained two teachers Rosie and Daisy (both pseudonyms) - in aspects of cognitive stylistics, including the textual attractor model as outlined above. We then collaborated on the design of a six-week, 15-lesson scheme of work, informed by the pedagogical principles and drawing on methods and concepts from cognitive stylistics. Rosie and Daisy delivered the lessons with their students, and these were filmed and then transcribed by me.

All transcriptions were analysed thematically and coded using NVivo software. The purpose of coding was to provide a way of indexing and organising the data, serving a useful practical endeavour in spotting patterns and connections across the dataset. In accordance with Elliot's (2018) call for a contextually-sensitive, pragmatic, 'decision-making' approach to coding, I used a blend of deductive and inductive methods, starting with some broad a priori themes (e.g. 'metalinguistic discourse') and allowing for the emergence of new themes as I coded (e.g. 'metalanguage used to assist in literary interpretations'). I allowed the data to drive the process and codes to emerge from the data but used my first-hand knowledge of being in the classrooms in order to help guide this. I made use of cognitive stylistic concepts to inform my code labels (e.g. 'discourse about world-building'), reflecting my commitment to cognitive stylistics not just as a pedagogy but as a way of describing classroom discourse itself. The final coding framework was built on the 15 lessons which formed the dataset, but given the specific research aims of this paper, I focus on data which derived from four lessons (explained further below), tagged under a sub-set of the broader coding framework. The codes which I draw on in the following discussion then, are shown in Table 1.

\begin{tabular}{|l|l|l|}
\hline Code label & Definition & Example \\
\hline $\begin{array}{l}\text { Discourse about } \\
\text { world-building }\end{array}$ & $\begin{array}{l}\text { Discourse referring to the way that } \\
\text { readers talk about the construction of } \\
\text { fictional worlds in their minds }\end{array}$ & $\begin{array}{l}\text { I pictured a soldier who was stumbling } \\
\text { down this trench and there was loads of } \\
\text { stuff around him and he could smell } \\
\text { horrible things and occasionally things }\end{array}$ \\
\hline
\end{tabular}




\begin{tabular}{|l|l|l|}
\hline & & $\begin{array}{l}\text { would appear and he would see these } \\
\text { things }\end{array}$ \\
\hline $\begin{array}{l}\text { Grammatical } \\
\text { analysis }\end{array}$ & $\begin{array}{l}\text { Discourse referring to the application } \\
\text { of grammatical concepts as an } \\
\text { analytical tool }\end{array}$ & $\begin{array}{l}\text { well he's in subject position so he's } \\
\text { doing all the verbs (.) things like kicked } \\
\text { and sniffed and things (.) they're all } \\
\text { action verbs (.) and he moves (.) } \\
\text { because of words like along and } \\
\text { through and all those verbs (.) so our } \\
\text { attention focuses on him as the text- } \\
\text { world changes }\end{array}$ \\
\hline $\begin{array}{l}\text { Memories, past } \\
\text { experiences and } \\
\text { intertextual } \\
\text { connections }\end{array}$ & $\begin{array}{l}\text { Discourse referring to memories and } \\
\text { past experiences from outside the } \\
\text { classroom, and where students make } \\
\text { intertextual connections }\end{array}$ & it reminded me of war films I've seen \\
\hline
\end{tabular}

\section{Table 1: Sub-selection of codes used to guide data selection}

The classroom data was triangulated with teacher interviews and my own field notes, in order to carry out a discursive evaluation of the pedagogy, its principles and the way it was actualised in the classroom. In the sections that follow, I focus on data generated from four lessons, two taught by each teacher, where students were reading and responding to The Rear-Guard by Siegfried Sassoon (1918). The broad purpose of the lessons was to draw students' attention to the ways in which language was combining with their own discourse-world knowledge in order to construct a reading experience. In order to help facilitate this and ensure that students' responses were anchored to the text, Rosie and Daisy introduced the textual attractor model as a 'tool' for students to account for how the texture and depth of the fictional world was unfolding. As is the growing tradition within cognitive stylistics, I combine my own introspective analysis of The Rear-Guard, using the textual attractor model to so, with reader-response data. This data is taken from the classroom, where teachers and students were using the model as a pedagogy.

\section{The texture of the trench}

The Rear-Guard

(Hindenburg Line, April 1917)

Groping along the tunnel, step by step,

He winked his prying torch with patching glare

From side to side, and sniffed the unwholesome air.

Tins, boxes, bottles, shapes and too vague to know;

A mirror smashed, the mattress from a bed;

And he, exploring fifty feet below

The rosy gloom of battle overhead.

Tripping, he grabbed the wall; saw someone lie

Humped at his feet, half-hidden by a rug.

And stooped to give the sleeper's arm a tug.

"I'm looking for headquarters." No reply.

"God blast your neck!" (For days he'd had no sleep.)

"Get up and guide me through this stinking place."

Savage, he kicked a soft, unanswering heap, 
And flashed his beam across the livid face

Terribly glaring up, whose eyes yet wore

Agony dying hard of ten days before;

And fists of fingers clutched a blackening wound.

Alone he staggered on until he found

Dawn's ghost that filtered down a shafted stair

To the dazed, muttering creatures underground

Who hear the boom of shells in muffled sound.

At last, with sweat and horror in his hair,

He climbed through darkness to the twilight air,

Unloading hell behind him step by step.

Upon encountering the text, readers build a text-world where they draw on their own discourse-world knowledge related to war, triggered by words such as 'battle', 'shells', '1917' and 'Sassoon'. In my own reading, this text-world is immediately immersive, in part triggered by the 'timeless' non-finite ing-clause with which it begins, and so displaces me immediately into the trench. My text-world is vivid and stable, even though I have no first-hand experience of trench warfare. The poem features an unnamed male soldier moving with difficulty through a hellish first-world-war trench, encountering dead bodies and various other objects which obstruct his dimly-lit path. One of the ways in which the poem achieves its texture of a nightmarish, dark and claustrophobic world is through the alignment and rapid shifting of a range of textual attractors across several dimensions. The trench acts as the main location in the text-world of the poem, providing the deictic backdrop for an array of objects and sensory inputs which function as textual attractors. These include the main character of the text-world, the soldier, realised as a pronoun ('he') occupying subject-agent position and so is an attractor in terms of empathetic recognisability, agency and topicality. The non-specific reference places him lower down the cline of definiteness and renders him anonymous, yet 'he' is high on the activeness scale, shifting his deictic centre as he moves through and eventually out of the tunnel. These movements are marked with prepositions (e.g. 'along', 'through') and transitive verbs (e.g. 'exploring', 'climbed'), as we track him through the trench. Material verbs denoting action (e.g. 'sniffed', 'grabbed', kicked', 'staggered') function as activeness attractors, as the solider interacts with objects around him that are largely from the lexical domain of DOMESTIC ENVIRONMENT (e.g. 'tins', 'boxes', 'a mattress'), and construe the trench as a home, not just a location of war. In stanza three he encounters a dead soldier who functions as a fullness attractor given the level of detail he is described in, marked though elaborated noun phrases ('a soft, unanswering heap', 'the livid face', 'blackening wound'), yet the fact that he is also ascribed no name renders him lower along the empathetic recognisability dimension. Contrast between silence and noise, and light and darkness is a significant textual pattern here. Against the backdrop of the dark trench appear occasional sources of light ('dawn's ghost', 'winked his prying torch', 'flashed his beam') and sound ('gloom of battle overhead', 'the boom of shells') which function as fleeting brightness, height and noisiness attractors and serve as reminders to the fighting above.

The horror of the trench then, is partly realised through the textual alignment and dynamism of attractors, underpinning the soldier's movements and interactions with the environment, the occasional flashes of light and his desire to be out of the trench, but the knowing of what lies above. There are, of course, other things to say about this poem, but given my focus here is on texture and textual attractors as a pedagogy, I now turn my attention to traces of this in classroom discourse.

\section{Texture in the classroom}

This section examines students' responses to the poem. It discusses the apparent facilitative benefits of a cognitive stylistic pedagogy in drawing students' attention to the felt texture of reading, and the kind of linguistic patterns responsible for this. It draws on data indexed with a selection of codes relevant to the research aims, namely 'discourse about world-building', 'grammatical analyses' and 'students' memories and past experiences'.

Following a reading of the poem, students began by discussing what kind of text-world the poem constructed for them, and how this related to their own schematic knowledge of war. This was 
an important springboard for the discussions that followed, because it grounded the discourse towards students' own readings and served to legitimise them as authentic readers (Giovanelli \& Mason 2015). Without the front-loading of contextual information supplied by the teacher or the immediate instruction to begin searching for grammatical features, students were given space to respond to the text on their own terms and allowed their own views, experience and discourse-world knowledge to be implicated in their reading (see Yandell 2014: 72). Despite the fact that none of the students had any first-hand experience of war, they were still able to draw on their cultural discourse-world and intertextual knowledge in order to construct a text-world. For instance, from Rosie's class:

Elizabeth: I pictured a soldier who was stumbling down this trench and there was loads of stuff around him and he could smell horrible things and occasionally things would appear and he would see these things (.) but it's so dark that you can't tell what is happening sometimes (.) and all of a sudden there's these noises from above (.) it reminded me of war films I've seen and yeah (.) it seems like a pretty awful place

\section{Extract 1: Elizabeth's text-world}

Before being explicitly introduced to the textual attractor model and its metalanguage, students were asked to discuss the kinds of things that were foregrounded for them. Elizabeth's turn above touches on the idea that textual correlates of bodily experiences and senses could function as attractors, talking about empathetic recognisability and activeness ('I pictured a soldier who was stumbling'), definiteness and fullness ('occasionally things would appear'), noisiness and height ('all of a sudden there's these noises from above'). The reporting of her fictional world is one where movement and spatial orientation are clearly important, as traced textually in my own stylistic analysis in the previous section. Other responses also tended to be in accordance with the notion of textual attractors, with students focusing on things such as the soldier and his movements, large objects and noise. Students were comfortable with the idea that these things could change, for instance:

Millie: $\quad$ well at the start the tunnel is foregrounded because that's the first thing so it kind of grabs our attention immediately and when we think of that word then we might think of like a battle and then at the end the battle is kind of foregrounded as he moves upwards into the air

Daisy: $\quad$ ok good do you want to give me a quote as an example where the battle becomes the foreground?

Millie: unloading hell and there was another one I can't find it now (2) oh booming shells and the rosy gloom of battle overhead

Daisy: definitely so at that moment those sounds come to the foreground

Minnie: it's like when the objects the tins and the bottles and things appear in the text it's like objects in front of each other just kind of dotted around like you see them but then they disappear a bit like in pop-up books when you have some things that just appear but then go

Ezra: $\quad$ yeah (.) it's like the person is moving and he's holding the torch so you can kind of see it it's like he is moving it side to side (.) and so we see what he sees (.) and the light of outside right at the end is like when he finally escapes the tunnel and that's the thing that he's been attracted to and the thing that he's moving towards like it's a glimmer of hope for him

\section{Extract 2: Millie, Daisy, Minnie and Ezra}

Students' use of spatial language (e.g. 'appear', 'pop-up', 'moving towards') and temporal language (e.g. 'at the start', 'at the end') demonstrate how they are reflecting on the deictic properties of textworld construction in terms of its depth and spatial arrangement as well as its dynamic nature, especially in how text-world entities shift into and away from the fore/background. What Extracts 1 and 2 suggest is that students appeared to have no problem in identifying things in a text that attracted 
their attention and were able to talk about these in terms of their own experiences of the texture of fictional worlds. The fact that the things they pick out correlate closely with Stockwell's original inventory suggest its intuitive nature, and that the experience of a fictional world is a kind of 'simulation' of the real world.

Following this exploratory discussion, students were then shown Figure 1, an adapted version of the inventory. The purpose of the inventory and the question prompts which accompany it was to further anchor student responses to the text, provide them with a metalanguage to describe the textural qualities of reading, and to explore the potential significance of a writer's linguistic choices and intentions.

\section{$<$ FIGURE 1 HERE $>$}

After being shown and talked through Figure 1, students discussed the extent to which their initial impressions were in accordance with the list of textual attractors. The data in Extracts 1 and 2 indicate that even without being explicitly shown the model, students were still accessing the conceptual basis of it, and the discussions that followed enabled them to make sense of their interpretations using cognitive stylistic concepts. For instance, one student remarked that the list 'matched the things that [he] said were attractors', and so legitimised the kind of initial responses that he had about the text but added a cognitive stylistic layer to these responses.

In particular, the model served a particularly facilitative function for the teaching of grammar, because it led with responses rather than grammatical terminology (see Cushing 2018a; Giovanelli 2014; Stockwell 2007). This enabled students to have their felt experiences of reading to drive their analyses, rather than first 'hunting' for grammatical features and then trying to work backwards to consider what the 'effect' of these were. The linguistic framework then, is only introduced 'once there is a clear motivation for it' (Stockwell 2007: 10), rather than reverse engineering 'effects' from 'features'. In Stockwell's inventory, the textual attractors that have the most clearly defined grammatical correlates are: agency, topicality, definiteness and activeness. Other attractors have less clearly defined grammatical characteristics - for instance, height is an attractor that is likely to be realised with spatial deictics, and attractors such as brightness and noisiness are likely to be realised with various modifying functions such as adverbs and adjectives.

Students generally agreed that the soldier constituted a good attractor because he was empathetically recognisable, was attributed agency, was in subject position, and was associated with various verbs of action. For instance:
Daisy:
[...] so what is the thing that is in subject position? Gabby?
Gabby: the soldier
Daisy:
the soldier (.) he is the subject in many of the clauses (.) so Gabby do you think he's a good textual attractor and if so why?
Gabby: well he's in subject position so he's doing all the verbs (.) things like kicked and sniffed and things (.) they're all action verbs (.) and he moves (.) because of words like along and through and all those verbs (.) so our attention focuses on him as the text-world changes (.) also I think we focus on him right from the beginning because he appears early and we track him all the way through (.) and I think that's because the soldier and his experience is the most important thing in the poem so we focus on him

\section{Extract 3: Daisy and Gabby}

In engaging in this kind of literary linguistic work, discourse about grammar became intertwined with discourse about the texture and experience of reading, contextualising it within the study of texts rather than it being something 'separate' (see Cushing 2019 for one criticism, especially in reference to the current UK curriculum). Students and teachers use grammatical metalanguage such as 'subject' and 'verb' here as a way of explaining the dynamic nature of texts in terms of what readers focus on, and what characters do and feel, incorporated alongside cognitive stylistic metalanguage ('textual attractor', 'text-world'), drawing connections between grammar, sensory input and experience. The 
motivation for the introduction of the textual attractor model lies in the fact that it provides conceptual interpretations of grammatical form, which are grounded in students' own sensory and spatial experiences of the actual world. What this data suggests then, is that if students are provided with the conceptual tools of cognitive stylistics, then this opens up the possibility of them thinking like a stylistician: paying equal attention to the linguistic patterns of texts and the felt experiences of reading, and using a metalanguage which is inherently descriptive.

The 'attractiveness' of the soldier was also the source of some debate, with students talking about the significance of the pronoun 'he' and the way this worked as a referent. At no point is the solider named, although Sassoon maintains him as occupying a subject-agent position throughout the text, referenced seven times through 'he'. Extract 4 illustrates students debating this:

Millie: $\quad[\ldots]$ I don't think he is foregrounded because he is referred to with pronouns instead of a name (.) so we can't recognise him and we don't know who he is (.) even though he is in subject position (.) he's just faceless

Daisy: $\quad$ ok so in your text-world he's not really foregrounded because we don't even know who he is we just know him through a pronoun (.) ok and did anyone disagree with that and think that he is foregrounded? go on Felix

Felix: $\quad$ I think he is foregrounded because everything in the poem is what he does it's not someone else (.) he does all of the verbs and they're all about actions it's he winked his prying torch he climbed through the darkness he went on the journey he experienced everything that we experience whilst we read it (.) it's not about a lot of different soldiers it's just about him (.) it's as if we're there with him as he moves

Daisy: $\quad$ ok yeah and so the differences are Felix says he is foregrounded by the repetition of the pronoun because we know that it is him where is Millie believes that his actions instead of foregrounded

Millie: $\quad$ ok but he's not really looked into as a person or as a name (.) it's just his actions he's just this person who's been told to do these things (.) to go to war (.) it could have been any soldier really like there's no personal feelings there is just him going through the tunnel

\section{Extract 4: Millie, Daisy, Felix}

Gabby's ideas that the soldier is a textual attractor because 'he's in subject position so he's doing all the verbs' and 'the soldier and his experience is the most important thing in the poem' show a nuanced understanding of how textual attractors are realised by different grammatical components, and how these contribute to a text-world. This idea is legitimised by Daisy, before Millie suggests that for her, 'he' is not an ideal textual attractor because of the 'pronouns instead of a name' meaning that 'we can't recognise him and we don't know who he is'. Felix's turn supports Gabby's earlier idea by highlighting the activeness of the soldier, looking in particular at the choice of verbs that relay his movements ('winked', 'climbed', etc.), and how this creates an intense sense of focus on the individual solider ('it's not about a lot of different soldiers it's just about him'). He reports feeling a sense of transportation here ('it's as if we are there with him'), in conceptually projecting himself into the text-world of the poem, an important cognitive operation in experiencing the emotional texture of fictional worlds (e.g. Gerrig 1993; Whiteley 2011). Millie's response to this touches on the idea that war can be a deeply anonymous experience that can strip soldiers of their identity, and how individuals can come to be one of millions in a conflict that places low-value on human life ('it's just his actions he's just this person who's been told to do these things'). It would seem then, that despite the grammaticality of the textual attractor as subject-agent, this is not always reflected in the felt experience of reading, yet the concept of attractors as an underpinning way of approaching the text was one way in which students were prompted to discuss this.

Again, grammatical discourse here serves a clear purpose: to facilitate students' discussions of texts and how the texture of fictional worlds unfolds. I argue that all of the extracts above provide illustrative examples of what Mercer (2000: 98) calls 'exploratory talk', whereby discourse participants become 'co-readers' (Peplow et al 2016: 99), using language to reflect on each other's 
contributions in critical yet productive ways, providing reasons for ideas, offering hypotheticals and questions. This kind of talk has clear textual traces: verbs of cognition ('e.g. I think'), interrogative adverbs ('e.g. why?'), modality, ('e.g. it could have been any soldier'), subordination ('e.g. because he is...'), conditionals ('it's as if we're there...'), and close references to the text itself. In the context of concept-driven grammar teaching, exploratory talk is especially useful because it has traces of discourse which constitute good cognitive stylistics: accounting for the felt experiences of a literary reading by paying close attention to textual detail, and using metalanguage in facilitating ways which uncover and reveal the depth of texts, rather than simply labelling things with no reference to linguistic meaning.

\section{Conclusions and implications for future research}

This paper has explored, for the first time, the application of texture and textual attractors (Stockwell 2009) within a cognitive stylistic pedagogy for English teachers. Texture, defined as the feeling of building and experiencing a fictional world, was a concept that resonated with what the teachers involved in this study believed in about their subject and its aims: to draw attention to the immersive and absorptive feelings encountered during, and the ways in which texts can invoke rich, real, emotional responses in the minds of readers. A cognitive stylistic pedagogy thus builds on 'classic' reader-response work (e.g. Rosenblatt 1978) but adds a textual, grammatical dimension in the insistence that responses are anchored to the text itself and offers a more precise set of terms for describing what happens in the mind during reading.

Data from the classroom suggested that one way of describing texture, Stockwell's model of textual attractors, provides an intuitive, embodied and accessible metalanguage which seems to me to be appropriate for young readers, or even, young stylisticians. It is my suggestion then, that the use of the textual attractor model offers pedagogical benefits in a variety of ways: it provides conceptual interpretations of grammatical form; it allows readers to describe their reading experiences in systematic ways; it presents a spatially, sensory and experientially-orientated grammar which is built on what readers already know about the world, and it makes consistent reference to the actual text under discussion. Although this paper has been limited to data generated from four lessons, this formed part of a larger project in which I set out a pedagogical and practical rationale for the place and value of cognitive stylistics in schools. Across this work, I have consistently argued for pedagogies which reject false divisions between 'language' and 'literature', reject the prescriptive and reductive ways that grammar is conceptualised on the current UK curriculum, particularly at primary level, and instead frame grammar as a as something intimately bound up with the textual evocations of reading, as a clause and discourse-level phenomena.

Although there has been an increased interest in the deployment of stylistics and cognitive stylistics to the secondary school classroom (see Cushing 2018b for one overview), it is important to consider some of the conditions and impositions surrounding this work. Firstly, I argue that any limitations are a result of structural issues in curriculum policy and teacher training rather than the pedagogy or the principles of cognitive stylistics itself. The teachers involved in this study were part of a collaborative, design-based research project which was sensitive to their own professional identities, subject specialisms and what they believed to constitute good practice, namely around the value of reader-response and contextualised grammar pedagogies. Because cognitive stylistics is unlikely to be a typical feature of English teachers' repertoires, it is imperative that teachers must have access to training if they are to develop their subject knowledge in this way (also see Cushing 2018b; Giovanelli 2016). Any training must be sensitive to the socio-political, cultural and professional contexts in which English teachers work, taking their professional identities and subject specialisms into account, and fully acknowledging macro-level policy, curricula and assessment pressures (Marshall 2016). Whilst this paper has argued for the place of cognitive stylistics and texture as an available pedagogy for English teachers, there remains much work to be done in building teachers' subject knowledge and confidence in linguistics and stylistics (see for example, Giovanelli 2016). This requires long-term investment and commitment by teachers, academics and policy makers, as well as a reconceptualisation of grammar and language as on the current curriculum.

Stockwell (2007) argues that stylisticians are 'really the only people equipped to teach literature itself' (2007: 23). This might invoke unsettled feelings in many teachers' minds, but the crux of the argument is undeniable: literature is made from language, and language creates mental 
experiences. Stylistics offers the conceptual and linguistic tools to describe how those experiences work. This way of thinking about literature, and the way of thinking about grammar as presented in this paper - as a sensory, bodily experience that helps to account for the way that readers respond to texts in the way they do - is perhaps likely to be somewhat different to mainstream discourses about grammar in English education. My response to this would be not in terms of trying to 'justify' this grammar pedagogy further, but instead by asking: why wouldn't we think of grammar in this way?

\section{Acknowledgements}

Thank you to the teachers and students who took part in this study, and to the school for granting permission for the research to take place. Thank you also to two anonymous reviewers for their useful feedback on an earlier version of this paper, and to Peter Stockwell for his encouragement in using this framework in this way.

\section{References}

Barab, S. (2014). Design-based research: a methodological toolkit for engineering change. In: Sawyer, K (ed). Handbook of the Learning Sciences, Vol 2. Cambridge, MA: Cambridge University Press, pp. 233-270.

Carter, R. (2010). Methodologies for stylistic analysis: practices and pedagogies. In: McIntyre, D (ed). Language and Style. London: Palgrave Macmillan, pp. 34-46.

Cushing, I. (2018a). 'Suddenly, I am part of the poem': texts as worlds, reader-response and grammar in teaching poetry. English in Education 52(1): 7-19.

Cushing, I. (2018b). Stylistics goes to school. Language and Literature 27(4): 271-285.

Cushing, I. (2019). Grammar policy and pedagogy from primary to secondary school. Literacy 53(3).

Cushing, I. (2020a, forthcoming). Re-telling text-worlds. In: Lambrou, M (ed). Narrative Retellings. London: Bloomsbury.

Cushing, I. (2020b, forthcoming). Recontextualising cognitive grammar for school teaching. In: Giovanelli, M., Harrison, C \& Nuttall, L. (eds). New Directions in Cognitive Grammar and Style. London: Bloomsbury.

Cushing, I \& Giovanelli, M. (2019, forthcoming). Integrating language and literature: a text world theory approach. Journal of Literary Education 2.

Dahl, R. (1988). Matilda. London: Johnathan Cape.

Elliot, V. (2018). Thinking about the coding process in qualitative data analysis. The Qualitative Report 23(11): 2850-2861.

Gavins, J. (2007). Text World Theory: An Introduction. Edinburgh: Edinburgh University Press.

Gavins, J. (2012). Leda and the stylisticians. Language and Literature 21(4): 345-62.

Gerrig, R. (1993). Experiencing Narrative Worlds: On the Psychological Activities of Reading. New Haven, CT: Yale University Press.

Giovanelli, M. (2010). Pedagogical stylistics: a text world theory approach to the teaching of poetry. English in Education 44(3): 214-231. 
Giovanelli, M. (2013). Text World Theory and Keats' Poetry. London: Bloomsbury.

Giovanelli, M. (2014). Teaching Grammar, Structure and Meaning: Exploring Theory and Practice for Post-16 English Language Teachers. London: Routledge.

Giovanelli, M. (2016). Developing beginning teachers' linguistic awareness: issues and practice in ITE. In: Giovanelli, M \& Clayton, D (eds). Knowing About Language: Linguistics and the Secondary English Classroom. London: Routledge, pp. 186-197.

Giovanelli, M. (2017). Readers building fictional worlds: Visual representations, poetry, and cognition. Literacy 51(1): 26-35.

Giovanelli, M \& Mason, J. (2015). 'Well I don't feel that': Schemas, worlds and authentic reading in the classroom. English in Education 49(1): 41-55.

Marshall, B. (2016). The politics of testing. English in Education 51(1): 27-43.

Mercer, N. (2000) Words and Minds: How We Use Language to Think Together. London: Routledge.

Myhill, D. (2018). Grammar as a meaning-making resource for improving writing. L1 Educational Studies in Language and Literature 18: 1-21.

Neurohr, B \& Stewart-Shaw, L (eds). (2019). Experiencing Fictional Worlds. Amsterdam: John Benjamins.

Pennycook, A. (2001). Critical Applied Linguistics: A Critical Introduction. London: Routledge.

Peplow, D., Swann, J., Trimarco, P \& Whiteley, S. (2016). The Discourse of Reading Groups: Integrating Cognitive and Sociocultural Perspectives. London: Routledge.

Rosenblatt, L. (1978). The Reader, the Text and the Poem. Carbondale and Edwardsville. Southern Illinois University Press.

Semino, E \& Culpeper, J. (2002). Cognitive Stylistics. Amsterdam: Benjamins.

Sassoon, S. (1918). The Rear-Guard. In: Counter-Attack, and Other Poems. London: William Heinemann, p. 8.

Stockwell, P. (2002). Cognitive Poetics: An Introduction. London: Routledge.

Stockwell, P. (2005). Texture and Identification. European Journal of English Studies 9(2): 143-53.

Stockwell, P. (2007). On teaching literature itself. In: Watson, G \& Zyngier, S (eds). Literature and Stylistics for Language Learners. London: Palgrave, pp. 15-24.

Stockwell, P. (2009). Texture: A Cognitive Aesthetics of Reading. Edinburgh: Edinburgh University Press.

Stockwell, P. (2016). Texture. In: Sotirova, V (ed). The Bloomsbury Companion to Stylistics. London: Bloombsury, pp. 458-473.

Wales, K. (2014). The stylistic tool-kit: methods and sub-disciplines. In: Stockwell, P \& Whiteley, S (eds). The Cambridge Handbook of Stylistics. Cambridge: Cambridge University Press, pp. 32-45. 
Werth, P. (1999). Text Worlds: Representing Conceptual Space in Discourse. London: Longman.

Whiteley, S. (2011). Text world theory, real readers and emotional responses to The Remains of the Day. Language and Literature 20(1): 23-41.

Xerri, D. (2013). Colluding in the 'torture' of poetry: shared beliefs and assessment. English in Education 47(2): 134-146.

Yandell, J. (2014). The Social Construction of Meaning: Reading Literature in Urban English Classrooms. London: Routledge. 